Article

\title{
Preparation and Characterization of New Electrically Conductive Composites Based on Expanded Graphite with Potential Use as Remote Environmental Detectors
}

\author{
Martin Prostredný ${ }^{1}\left(\mathbb{D}\right.$, Igor Krupa ${ }^{2}$ and Zdenko Špitalský ${ }^{3, * \mathbb{D}}$ \\ 1 Department of Chemical and Process Engineering, University of Strathclyde, 75 Montrose Street, \\ Glasgow G1 1XJ, UK; martin.prostredny@strath.ac.uk \\ 2 QAPCO Polymer Chair Center for Advanced Materials, Qatar University, Doha 2713, Qatar; \\ Igor.Krupa@qu.edu.qa \\ 3 Polymer Institute, Slovak academy of Sciences, Dúbravská cesta 9, 84541 Bratislava, Slovakia \\ * Correspondence: zdeno.spitalsky@savba.sk
}

Received: 3 August 2020; Accepted: 15 September 2020; Published: 17 September 2020

\begin{abstract}
The presented paper is focused on studying electrically conductive composites based on an elastomeric matrix and expanded graphite as the filler. A potential application as an environmental remote detector was studied. The influence of filler particle size, film thickness, detector length, temperature, and the amount of oil on the detector response rate were explored. Peel tests were performed in order to investigate the adhesion of prepared detector films to different materials. Expanded graphite with average particle size $5 \mu \mathrm{m}$ was chosen for the experiments due to its fastest response. Decreasing the detector film thickness has caused an increase in the response rate but also a decrease in the signal measured. The response rate of the detector system was in a practical range even for lower temperatures. From the obtained data, the proposed detector seems to be suitable for a practical application.
\end{abstract}

Keywords: elastomer; expanded graphite; environmental sensor; engine oil; composite

\section{Introduction}

Water contamination by crude oil and petroleum products is becoming an increasing environmental problem [1-3]. Even though there have been methods developed that help with oil removal from spillages, such as chemical dispersion [4,5], we still need to know that oil contamination has happened in order to start the clean-up process. For that reason, a notable effort has been put into the development of sensing systems capable of detecting these organic pollutants. One group of sensors and detectors that are currently in use are systems capable of detecting the pollution remotely. The equipment can be mounted e.g., on a drone, plane, or a satellite. Most commonly used techniques for remote pollution detection utilize optical image analysis and electromagnetic radiation from the microwave to ultraviolet range [6-8]. Disadvantages of the aforementioned methods include high costs and reduced efficiency for wide area surveillance due to limited coverage. However, more types of systems are being developed for sensors and detectors located in the place of contamination. These can be based on different materials and working principles such as for a flowing set-up, capacitance sensors [9-11] can be used using a measurement frequency high enough to obtain the required sensitivity and a recent system employing a photo-ionization detector [12], suitable for mid to high concentrations. However, these are generally suitable for systems with higher oil-water ratio flowing through a pipe. The majority of oil contamination occurs in oceans and seas, so a variety of systems applicable on bodies of water have been studied and developed. One kind of such sensors uses fluorescent spectroscopy as the oil sensing technology $[13,14]$, where the sample has to be collected and analyzed in a laboratory. 
An interesting approach proposed a so-called spilled oil tracking autonomous buoy, the task of which includes drifting along with the oil slick and sending meteorological and oceanographic data from its surroundings to a land base in real time [15].

A number of sensors and detectors based on a polymeric matrix and an electrically conductive filler are used as vapor sensors as well. The working principle of such systems is based on swelling of the polymeric matrix in presence of a model substance [16-19]. The same mechanism can also work for some elastomers/rubbers that swell in oil. Even though this is a negative effect for a rubber seal, it can be exploited for monitoring electric current changes.

This paper presents preparation and study of a novel type of environmental detector based on an elastomeric matrix and expanded graphite, suitable for detection of water contamination caused by petroleum and its constituents and derivatives. Other research groups have previously used a model mixture of benzene, toluene, ethylbenzene, and xylene isomers $[20,21]$ and our group previously utilized vegetable oil [22] in order to test the performance of a detector system. In this work, a commercial engine oil is used as a representative of a real pollutant. The effect of different detector film lengths was studied, since longer films might be required due to the presence of waves. Furthermore, the influence of temperature on detector performance within a temperature range that covers cold nights and hot days was investigated here.

\section{Materials and Methods}

\subsection{Materials}

A linear triblock styrene-isoprene-styrene (SIS) copolymer Kraton D1165 P (Kraton Corporation, Houston, TX, USA) was used as the elastomeric matrix. Expanded graphites with average particle size $5 \mu \mathrm{m}$ (GFG 5), $50 \mu \mathrm{m}$ (GFG 50), $200 \mu \mathrm{m}$ (GFG 200), and $500 \mu \mathrm{m}$ (GFG 500), used as fillers, were purchased from SGL CARBON GmbH (Wiesbaden, Germany). Following materials were used as peel test substrates: polyethylene terephthalate foil Tenolan OAN (Fatra, a.s., Chropyně, Czech Republic), polyvinyl chloride powder Slovinyl E 711 (Fortischem a. s., Nováky, Slovakia), polyamide 6 foil Zellamid ${ }^{\circledR} 202$ (Zell-Metall GmbH Engineering Plastics, Kaprun, Austria), biaxially oriented polypropylene foil Tatrafan ON (Terichem a. s., Svit, Slovakia), low-density branched polyethylene foil Bralen FB 2-17 (Slovnaft a. s., Bratislava, Slovakia), and aluminum foil (EKOMT s.r.o, Čadca, Slovakia). In order to connect a detector film to a DC power source and a multimeter, an electrically conductive adhesive GRAVIPOL-electro made in-house at Polymer Institute SAS (Bratislava, Slovakia) was used. Toluene (Mikrochem s.r.o., Pezinok, Slovakia) was used as a solvent for the polymer matrix. An engine oil Madit Super SAE 10W-40 (Slovnaft, a.s., Bratislava, Slovakia) was used as a model substance to test the response of prepared detectors.

\subsection{Methods}

\subsubsection{Polymer Composite Preparation}

Polymer composite films were prepared using solvent casting technique. All the prepared samples contained $20 \mathrm{w} / \mathrm{w} \%$ of filler/matrix. For the detector films, $5 \mathrm{~g}$ of polymer was left to swell in $5 \mathrm{~mL}$ of toluene overnight. A mixture of $1 \mathrm{~g}$ expanded graphite, used as a filler, and $20 \mathrm{~mL}$ toluene was ultrasonicated for 15 min using an ultrasonic device Hielscher $400 S$ with a probe Sonotrode H7, both supplied by Hielscher Ultrasonics (Teltow, Germany). A water bath containing ice was used to keep the mixture temperature down during the sonication, in order to avoid solution overheating. The toluene mixture containing a dispersed filler was mixed with the swollen polymer and put on a magnetic stirrer for the polymer to dissolve, while slightly heated. The surface of polyethylene terephthalate (PET) foils was cleaned with toluene and a paper towel in order to remove any dirt and grease, and each foil was attached to a horizontally aligned table. After the polymer was completely dissolved, a sufficient amount of the mixture was poured on the PET foil. A film applicator was used 
to ensure a uniform thickness of the prepared film. A picture of the used film applicator is shown in Figure 1. Prepared films were first left to dry at ambient temperature and subsequently transferred to a vacuum drying oven preheated to $60^{\circ} \mathrm{C}$. The samples were left to dry in the oven under a vacuum until the next day.

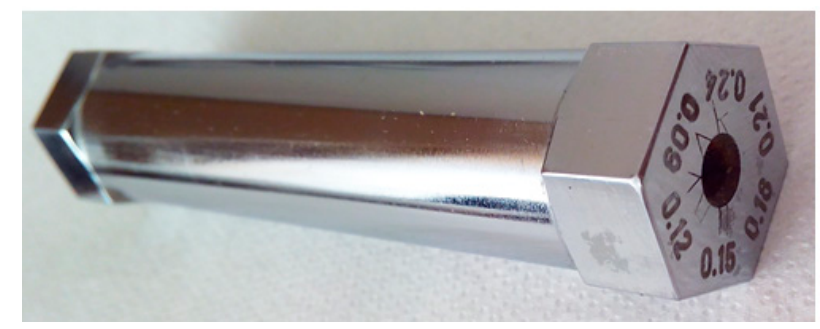

Figure 1. The film applicator used for making thin composite films.

\subsubsection{Composite Film Thickness Measurements}

The thickness of the prepared composite films was determined using an optical digital microscope from Shenzhen Hong Feng Sheng Electronic Technology Co., Ltd. (Shenzhen, China). The microscope was calibrated prior to measurements and the detector film thickness was measured using a 500x magnification. Each sample thickness was measured at six different locations and the final thickness was calculated as the average along with its standard deviation.

\subsubsection{Detector Response Measurements}

First, a $1 \mathrm{~cm}$ wide strip was cut from the films prepared in the previous step. In order to connect the samples to a DC power supply and a multimeter, a copper wire was glued to the surface using an electrically conductive adhesive Electropol (Polymer Institute, Slovak Academy of Sciences, http://www.polymer.sav.sk/gravipol/). The distance between the copper wire contacts was kept at $3 \mathrm{~cm}$ unless stated otherwise. The voltage at the DC power supply Protek DC 3006 (Protek Test and Measurement, Allendale, NJ, USA) was set to 10 V. A multimeter APPA305 (APPA Technology Corp., New Taipei, Taiwan) was connected to a computer and was used to measure the electric current flowing through the samples. The sample strips connected in this fashion were subsequently used for measuring their response rate as detectors. Commercially available engine oil Madit Super SAE $10 \mathrm{~W}-40$ was used as the testing substance. A schematic of the experimental set-up is shown in Figure 2.

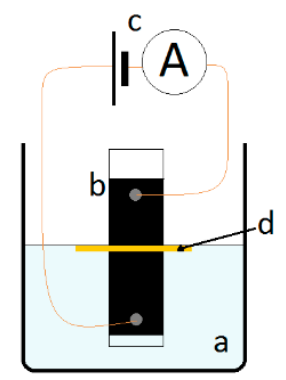

Figure 2. A schematic of the detector response rate measurement set up, (a) deionized water, (b) sample strip on polyethylene terephthalate (PET) foil, (c) DC power supply and multimeter connected to the sample with copper wires, (d) oil droplet on water surface.

\subsubsection{Peel Test Sample Preparation}

The samples used for peel tests were prepared in a similar way as the detector samples. The materials used as studied surfaces were polyethylene terephthalate (PET), polyvinyl chloride (PVC), polyamide 6 (PA6), biaxially oriented polypropylene (BOPP), aluminum (Al), and low-density polyethylene (LDPE). The surface materials were used as received, except for PVC films, which were 
prepared by solution casting on degreased glass panes from a tetrahydrofuran (THF) solution. A mixture of ultrasonicated filler GFG5, toluene, and pre-swollen polymer was prepared in the same way as for the composite films for detector samples, as described above. The studied surface materials were fixed on a horizontally aligned table and their surface was cleaned using toluene. Afterwards, a film of the composite mixture was spread on the surface using the film applicator with the largest wet film thickness $(0.24 \mathrm{~mm})$. This step was repeated two more times after leaving each layer to dry, in order to create thicker films. These air-dried samples were put into a vacuum oven preheated to $60^{\circ} \mathrm{C}$ and dried under vacuum until the next day. The dried films were cut into $1.5 \mathrm{~cm}$ wide strips. In order to be able to peel off the composite layer from the studied surface, a PVC veneer was adhered to the film using a compression mold press heated to $60^{\circ} \mathrm{C}$ with a $30 \mathrm{kN}$ force applied for $30 \mathrm{~s}$. The samples prepared in this way were used for the peel test measurements.

\subsubsection{Peel Tests}

The samples were prepared as described in the previous section. The PVC veneer was attached to the bottom fixture wheel and the tested material was fixed in the top clamp, as shown in Figure 3. In the case of PA6, the arrangement was changed due to a higher stiffness of PA6 than PVC veneer, so in this case, the PVC veneer was held in top clamps and PA6 was fixed on the wheel.

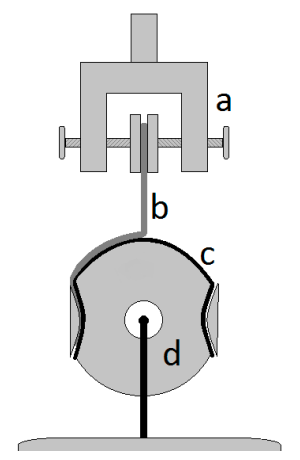

Figure 3. Schematic of the peel test set-up: (a) top clamp, (b) polymer composite sample, (c) polyvinyl chloride (PVC) veneer, (d) bottom wheel fixture.

The bottom part for fixing the sample is a wheel, which is free to rotate and ensures a constant $90^{\circ}$ peeling angle. The width of all the used sample strips was $1.5 \mathrm{~cm}$ and the test speed was set to $10 \mathrm{~mm} / \mathrm{min}$. At least six samples were analyzed for each material and an average value was calculated from these results.

\section{Results and Discussion}

In this section, the obtained results will be shown and discussed along with their significance. The presented experimental section is based on our previous research [23]. Initially, we studied the influence of the filler particle size in order to select the optimal filler for the subsequent experiments. The effect of composite film thickness was then examined and the optimal value is discussed. The next section focuses on the investigation of the detector length effect as longer detectors may be required in real life applications rather than small-scale laboratory samples, due to the potential presence of waves at the water surface of lakes or seas. The following parameter analyzed was the temperature of the set-up. Afterwards, we considered if the amount of oil has an effect on the response rate. In the last section, peel tests were performed to ensure that the prepared composite films exhibit sufficient adhesion to different surfaces that could serve as base materials.

The response of the detectors is measured in this work as the time-dependent decrease of electric current passing through the sample. In order to compare different samples in a better way, a parameter $t_{1 / 2}$ is introduced, defined as the time required for the current to drop to half of its initial value. We have 
also compiled data concerning initial values of the current flowing through the samples, $\mathrm{I}_{0}$. These two parameters aid in optimizing the detector performance, aiming for fast response rate, by minimizing the value of $t_{1 / 2}$, while maintaining sufficiently high value of initial electric current, distinguishable from noise. Previous (unpublished) long-time tests in pure and salt water have confirmed that there is no effect on conductivity of the tested polymer composites because of the presence of water, with or without salt. Therefore, this suggests that all impacts described below are the result of interactions of oil with prepared polymer composite detectors.

\subsection{Particle Size}

The samples for determining the effect of filler particle size on the response rate of the detectors contained expanded graphites GFG 5, GFG 50, GFG 200, and GFG 500, where the numbers indicate the average size of the filler particles in micrometers. The samples were prepared using the film applicator with $0.24 \mathrm{~mm}$ wet film thickness. Obtained results comparing the effect of different filler particle sizes are shown in Figure 4. The error bars around the curves indicate the standard deviations of the measurements.

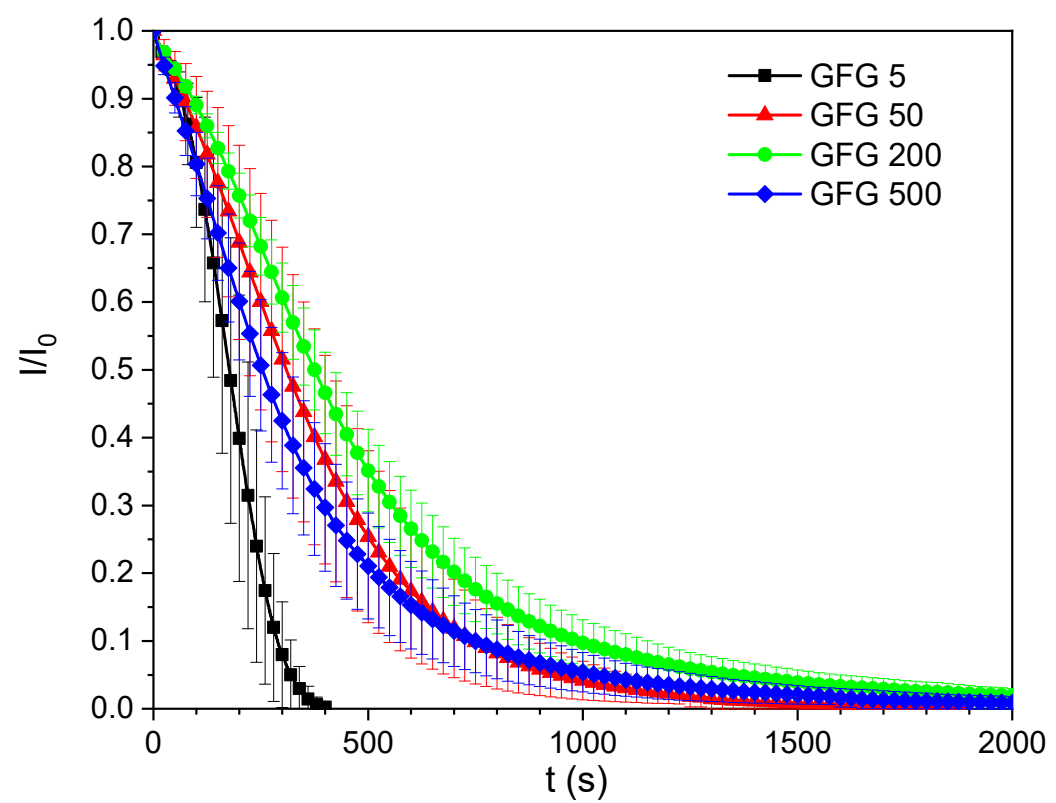

Figure 4. Change of relative current $\mathrm{I} / \mathrm{I}_{0}$ with time $\mathrm{t}$ for different filler particle sizes with data points corresponding to mean values and their standard deviation values (error bars) from three experiments.

From the graph in Figure 4, it is evident that the films containing the smallest filler particle size exhibited the fastest decrease of current when exposed to oil. The signal decrease to $50 \%$ for this sample (GFG 5) occurs after around $3 \mathrm{~min}$, which is two times faster than for the largest particle size (GFG 500). This could be explained by better distribution of smaller particles than the larger ones [24-26]. All of the measured data exhibit a sigmoid shape of the curve with a fast decrease of the electric current in the initial part, followed by a slower decrease in an exponential decay pattern.

From the obtained data, the dependence of the parameter $t_{1 / 2}$ and the initial current flowing through the samples $I_{0}$ on the filler particle size were analyzed (Figure 5). 


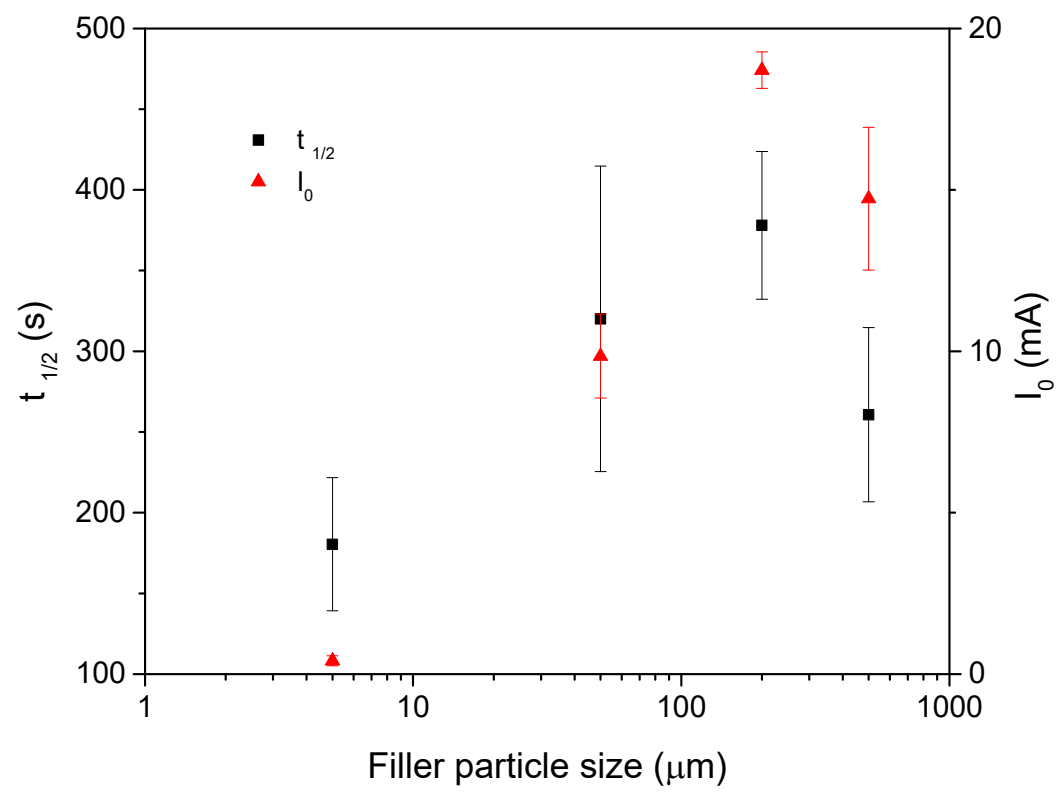

Figure 5. Dependence of the parameter $t_{1 / 2}$ and the initial current value $I_{0}$ on the filler particle size (axis in logarithmic scale) with data points corresponding to mean values and their standard deviation values (error bars) from three experiments.

From the graph in Figure 5, it is apparent that with increasing the filler particle size up to $200 \mu \mathrm{m}$, the response rate of the detector film decreases. For the fillers GFG 5, GFG 50, and GFG 200, the value of the initial current rises with increasing particle size, though the value for GFG 500 is somewhere between the values for GFG 50 and GFG 200. This could be explained by a different distribution of filler particles within the elastomeric matrix. A similar effect was observed by Kratochvila [27], where the effect was described by a higher tendency of the filler to create aggregates. The results for smaller particles are also in accordance with other studies [28-30], which proposed a higher probability to form a conductive network with smaller particles rather than with larger ones.

Concluding from the obtained information, the GFG 5 filler was chosen for all subsequent experiments due to its fastest response. Even though the initial current value was the lowest one, it was still a practically measurable value.

\subsection{Film Thickness}

The composite film thickness was observed to have a significant influence on the detector performance. For this purpose, samples with varying thickness were prepared, namely using the film applicator gap sizes $0.09,0.12,0.15,0.18,0.21$, and $0.24 \mathrm{~mm}$. Using an optical microscope, the real thickness of the prepared dried films was determined. The acquired values of measured film thickness with their respective gap sizes are summarized in Table 1. All values of the dried film thickness are equal to $17.5 \pm 1.0 \%$ of the respective film applicator gap.

Table 1. Film applicator gap sizes with the corresponding real film thicknesses.

\begin{tabular}{ccc}
\hline Film Applicator Gap [mm] & Film Thickness [mm] & Standard Deviation of Film Thickness [mm] \\
\hline 0.09 & 0.016 & 0.002 \\
0.12 & 0.022 & 0.003 \\
0.15 & 0.028 & 0.004 \\
0.18 & 0.030 & 0.003 \\
0.21 & 0.037 & 0.002 \\
0.24 & 0.039 & 0.004 \\
\hline
\end{tabular}


As expected, increasing the detector film thickness led to an increase in the response time. While the sample prepared with the highest thickness required approximately $3 \mathrm{~min}$ for the electric current to drop to half of its initial value, the $t_{1 / 2}$ for the thinnest sample was as low as $5 \mathrm{~s}$. This represents a very fast response compared to the current analytical methods used for the determination of oil pollutants in water [21].

Similarly, as for the filler particle size samples, the dependence of the parameter $t_{1 / 2}$ and $I_{0}$ on the thickness of the film was plotted and the results are summarized in Figure 6.

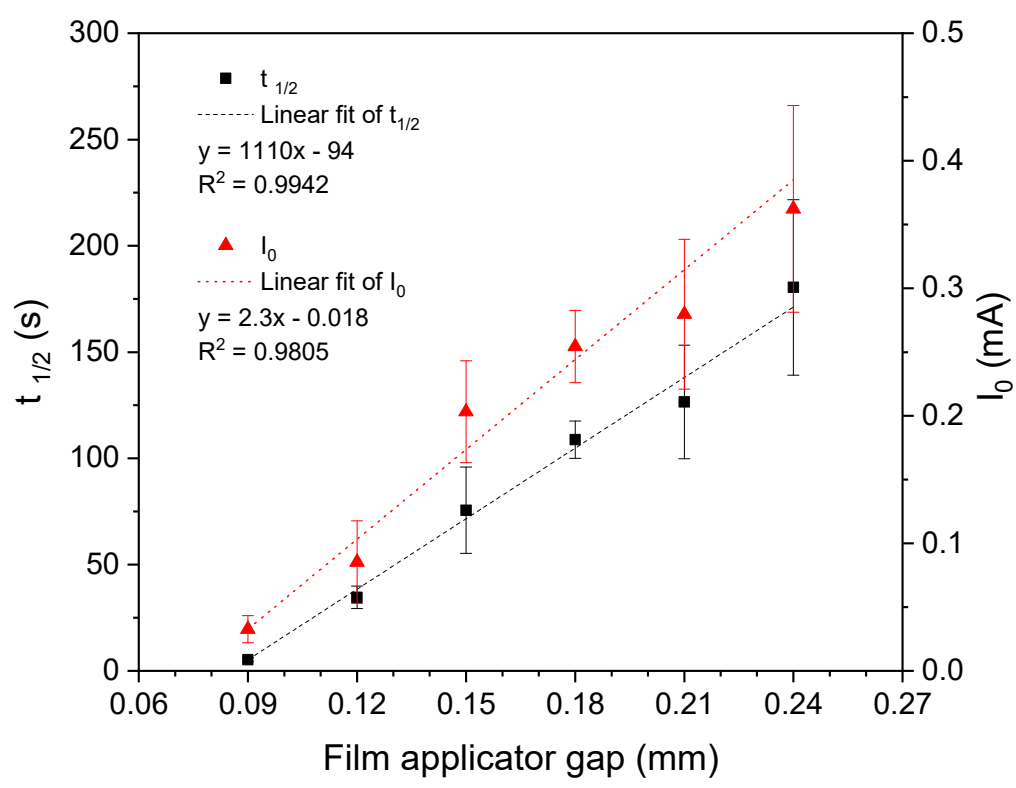

Figure 6. Dependence of the parameter $t_{1 / 2}$ and the initial value of current $I_{0}$ on film thickness with data points corresponding to mean values and their standard deviation values (error bars) from three experiments.

Analyzing the data in Figure 6 confirmed that the values of the parameter $\mathrm{t}_{1 / 2}$ and $\mathrm{I}_{0}$ increase with increasing film thickness. For both data series, linear fits were performed and the equations along with the corresponding coefficients of determination $R^{2}$ are shown in Figure 6. Both parameters, $t_{1 / 2}$ and $I_{0}$, are both crucial for a practical application and therefore, it is necessary to find an optimal value of film thickness that leads to an optimal ratio of these attributes. Additionally, it is essential to mention that with increasing film thickness, the standard deviation of the measurements increased as well. The electric current increased with rising film thickness due to an increase in the detector cross-sectional area. Likewise, an increase in the detector response time, and thus $\mathrm{t}_{1 / 2}$, can be explained by increasing volume of the composite film swollen by the oil. The balance between these two parameters would ensure a sufficiently fast response of the detector along with a high enough value of the electric current, overcoming the signal noise influence.

\subsection{Detector Length}

As discussed above, since longer detectors than the ones used in the previous sections $(3 \mathrm{~cm})$ may be required in practice, due to the presence of waves on the surface of lakes, rivers, and seas, detectors with different distances between the contacts were prepared. The wet film thickness and the filler content were fixed at $0.24 \mathrm{~mm}$ and $20 \mathrm{w} / \mathrm{w} \%$, respectively. The only parameter varied in this section was the aforementioned contact distance. The lengths studied here were 3, 9, 30, and $90 \mathrm{~cm}$.

From Figure 7, it can be seen that for the detectors with length 3,9 , and $30 \mathrm{~cm}$ the parameter $\mathrm{t}_{1 / 2}$ increases with the increasing detector length. However, the longest detector, with the contacts $90 \mathrm{~cm}$ apart, exhibited an even lower value of $t_{1 / 2}$ than the value observed for the shortest detector. This can be explained by the lowest value of the initial current measured for the longest sample. 


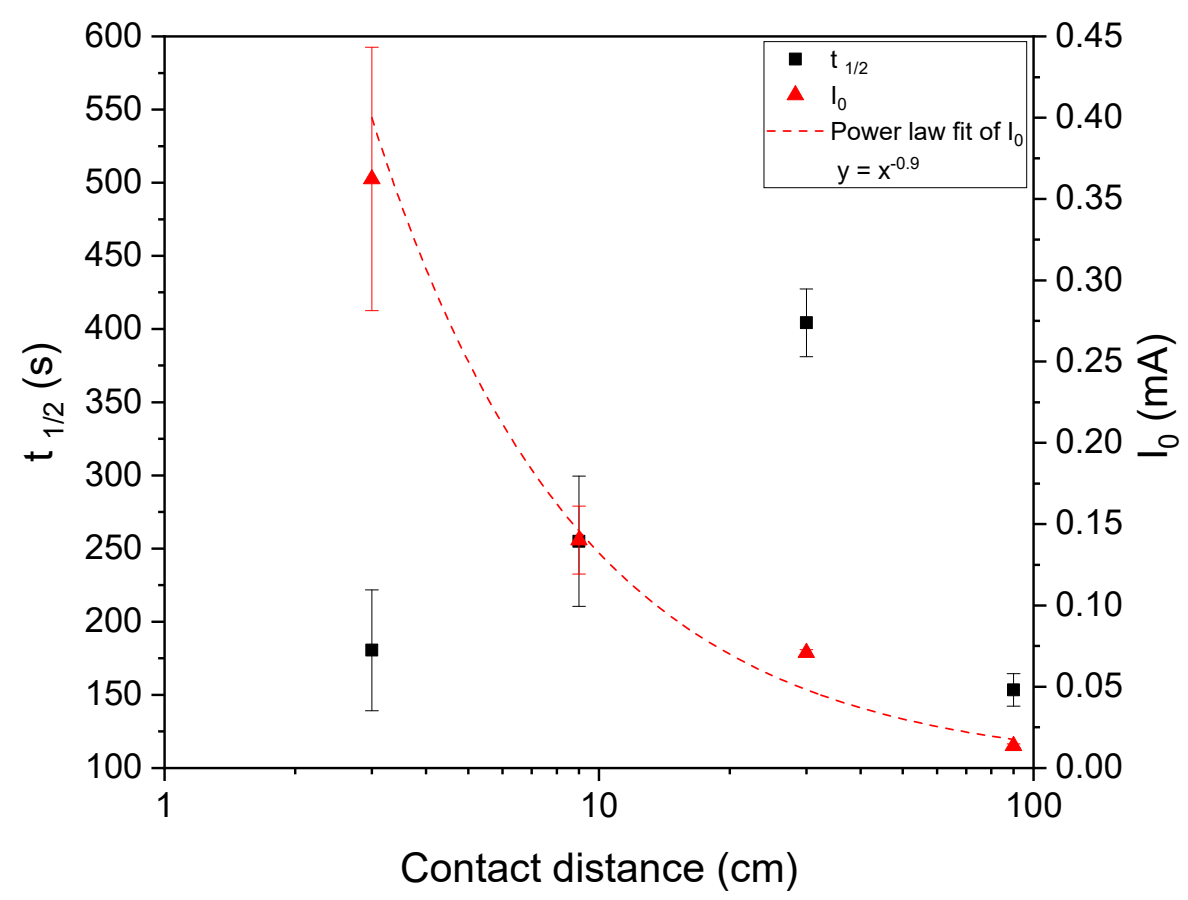

Figure 7. Dependence of the parameter $t_{1 / 2}$ and the value $I_{0}$ on the contact distance along with a power function fit for $\mathrm{I}_{0}$ data for contact distances $3,9,30$, and $90 \mathrm{~cm}$ with data points corresponding to mean values and their standard deviation values (error bars) from three experiments.

It is indeed confirmed that the current flowing through the longest sample is the lowest one. There is a noticeable correlation of the $\mathrm{I}_{0}$ data with a fitted exponential decay function, as can be seen in Figure 7. The results for films with length up to $30 \mathrm{~cm}$ suggest that with increasing the detector length, its response time rises. However, since the flowing current gradually decreases with increasing detector length, the low value of current for the detector with length $90 \mathrm{~cm}$ eventually takes over and the drop in electric current is, therefore, faster.

From a practical point of view, there should be an optimal length where the current value is high enough for the measurement but its lower value leads to a faster response time. In order to implement longer detectors, some other parameter would have to be modified, such as increase in the filler content or in the film layer thickness.

\subsection{Temperature}

In real-life outdoor applications, the temperature of the surroundings can vary in a relatively broad range (from lower temperatures during winter to higher temperatures during summer) and quite often (during day and night). Therefore, the influence of temperature on the detectors was explored. The lower temperature limit was set to $5^{\circ} \mathrm{C}$, and was limited by the freezing point of water, and the upper limit of $35^{\circ} \mathrm{C}$ was chosen as the temperature above an open body of water is unlikely to go much higher. The effect of temperature on the parameter $t_{1 / 2}$ is presented in Figure 8 . The samples were prepared using the film applicator with $0.24 \mathrm{~mm}$ wet film thickness.

Plotting the data, a gradual decrease of the parameter $t_{1 / 2}$ with temperature can be observed. While it took around $10 \mathrm{~min}$ for the current to reach half of its initial value for the detector at $5{ }^{\circ} \mathrm{C}$, at $35^{\circ} \mathrm{C}$ it took only around $2 \mathrm{~min}$. At lower temperatures, the oil viscosity is higher the diffusion processes are slower, leading to the slower response of the detector at lower temperatures. Nevertheless, the value of $10 \mathrm{~min}$ is still acceptable for real time sensing.

This suggests that the proposed detector system is applicable in a broad enough temperature range for real life applications. However, at lower temperatures, a slower response has to be taken into account. 


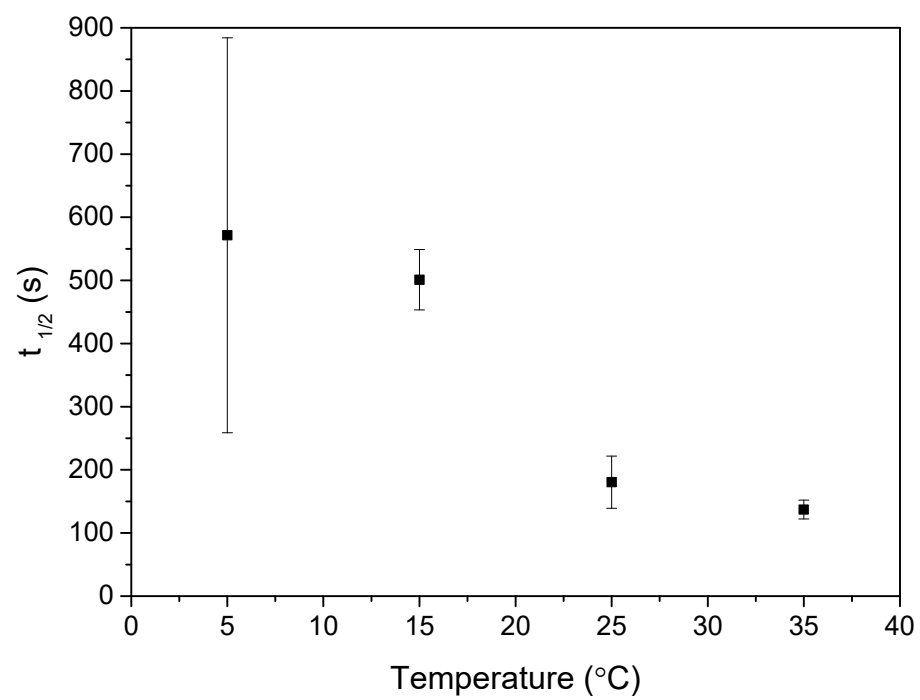

Figure 8. Dependence of the parameter $t_{1 / 2}$ on temperature with data points corresponding to mean values and their standard deviation values (error bars) from three experiments.

\subsection{Amount of Oil}

The last influence on the response rate of the prepared detector system studied was the amount of oil present. It is important to know if the investigated system is sensitive to a change in the amount of oil present and if it could be used to repeatedly determine the scale of contamination, as a sensor, or if it is independent on the amount of oil and thus could be used only as an indicator of the presence of oil, as a detector. For this purpose, samples were prepared using the $0.24 \mathrm{~mm}$ gap of the film applicator. A $5 \mathrm{~mL}$ graduated cylinder was used as the vessel for water due to its small cross-sectional area.

Again, a dependence of the parameter $t_{1 / 2}$ was plotted against the amount of oil to explore any trends present. Looking at the data plotted in Figure 9, it is confirmed that there is no link observed between the amount of oil and the response time of the detector. The difference in response time for the lowest and the highest amount of oil, which differ by two orders of magnitude, is negligible compared to differences caused by different composite film thicknesses. However, it is worth noting that this system was able to detect amounts of oil as low as $0.01 \mathrm{~mL}$, which corresponds to a layer of oil slick less than $1 \mathrm{~mm}$ thick, thus, making it a sensitive detector even though it cannot provide the information about the scale of contamination.

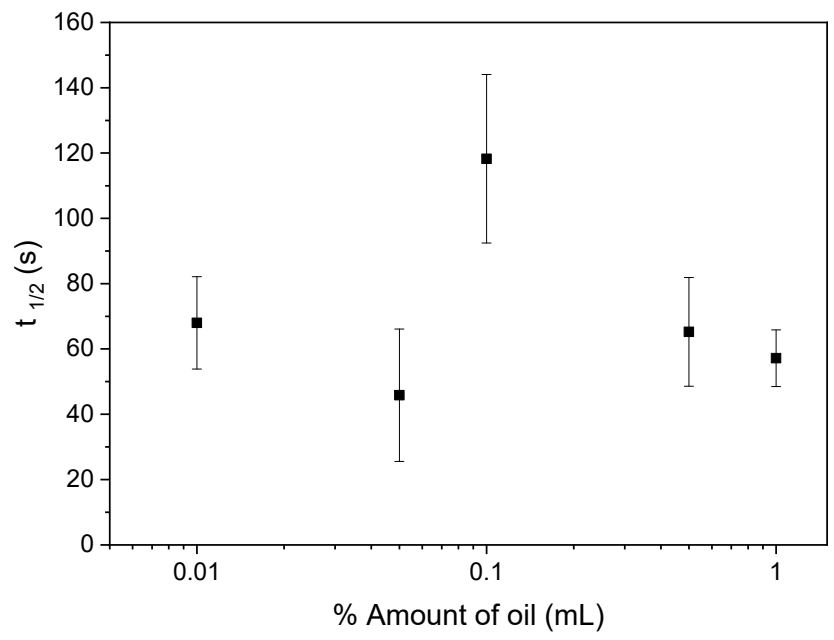

Figure 9. Dependence of the parameter $t_{1 / 2}$ on the amount of oil present with data points corresponding to mean values and their standard deviation values (error bars) from three experiments. 
The values of response rate are comparable to response rates of other sensors that were previously reported for the vapor phase $[17,18,31]$.

\subsection{Peel Tests}

In practical applications, it is very likely that the proposed detector film would be attached to a surface of a buoy or a boat. The surface of such objects can be made from various materials and therefore, the adhesion of the prepared composite film to various surfaces was studied, namely polyvinyl chloride (PVC), polyamide 6 (PA6), biaxially oriented polypropylene (BOPP), aluminum foil (Al), polyethylene terephthalate (PET), and low-density polyethylene (LDPE). Acquired values of peel force are shown in Figure 10.

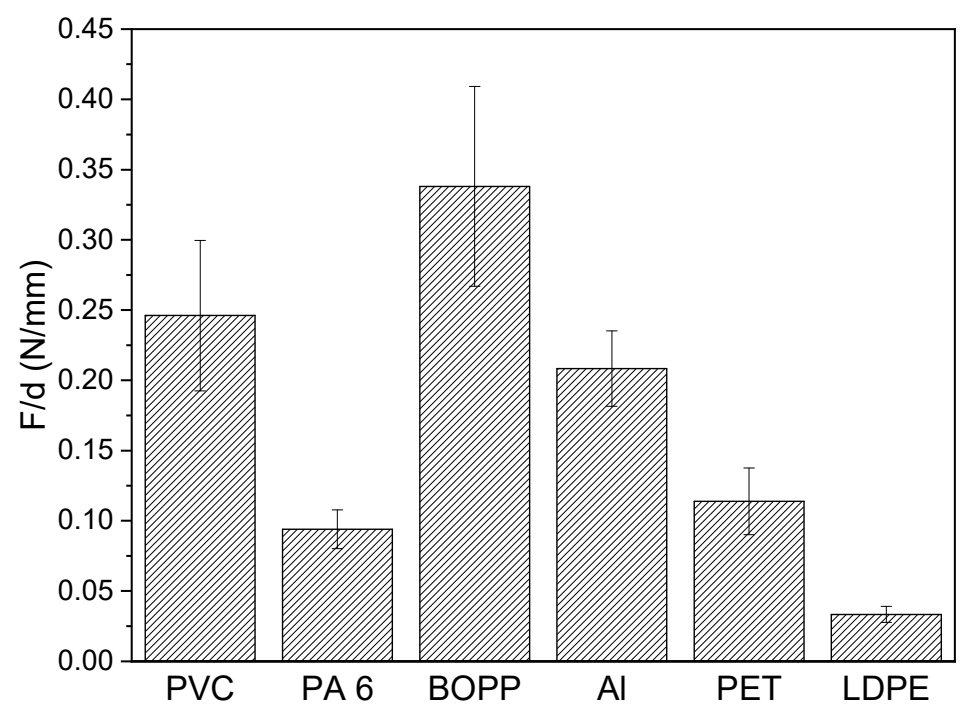

Figure 10. Peel test results for measured surfaces with peel force/width as the studied quantity with standard deviation values (error bars) from three experiments.

The results in Figure 10 show relatively high values of peel force, indicating good adhesion between the composite layer and the different polymer materials. It is important to note that for BOPP, the value would be even higher because the composite was peeling off from the PVC veneer rather than the BOPP surface. Therefore, the force holding the composite layer to the BOPP surface was even higher than the value measured in the experiment. The highest value obtained, corresponding to BOPP, was almost $0.34 \mathrm{~N} \cdot \mathrm{mm}^{-1}$. Still, significantly high values were achieved for PVC and Al surfaces as well. Somewhat lower values were observed for PET and PA6 and the lowest peel force was found for LDPE, being one order of magnitude lower than the value for BOPP.

In order to put the obtained results into perspective, the values were compared to results reported for other materials. Kim et al. obtained maximum adhesion around $0.49 \mathrm{~N} \cdot \mathrm{mm}^{-1}$ for chromium/copper films on a silicon substrate and around $0.69 \mathrm{~N} \cdot \mathrm{mm}^{-1}$ for polyamic acid on a copper foil [32]. Kinloch et al. studied polyethylene adhered to the surface of a PET substrate using an adhesive and achieved a maximum adhesion value around $0.038 \mathrm{~N} \cdot \mathrm{mm}^{-1}$ [33]. Poh with his team investigated adhesion of filled epoxidized natural rubber on a PET substrate. For samples filled with calcium carbonate, the highest adhesion values were around $0.045 \mathrm{~N} \cdot \mathrm{mm}^{-1}$ [34] and for rubber filled with coumarone-indene resin, the values were reported around $0.025 \mathrm{~N} \cdot \mathrm{mm}^{-1}$ [35]. From these results, we conclude that the composite film proposed here exhibited sufficiently high adhesion to the studied materials. The selected surfaces represent materials that could be used for a buoy surface, the surface of a boat or a ship hull, with the detector most likely placed at the waterline. Hence, a solution of the matrix and the filler could be used as a coating that could subsequently serve as the detector after drying. 


\section{Conclusions}

- The influence of the filler particle size was studied with the best performance observed for the detector system with the smallest particle size.

- Investigating samples with different film thickness, ranging from 16 to $39 \mu \mathrm{m}$, showed that increasing the layer thickness led to a decrease in the detector response rate. However, the electric current drops with decreasing detector thickness, and for thinner samples, the electric current was significantly influenced by the presence of noise. Therefore, it is necessary, for practical applications, to find an optimal balance between the value of the electric current and the detector response rate.

- For real life applications, longer detectors, comparable to water waves, might be required. Hence, detectors with different lengths were prepared and tested. It was observed that increasing the detector length until $30 \mathrm{~cm}$ caused the response rate to decrease. The longest sample exhibited the fastest response; however, this was caused by the lowest electric conductivity of this sample. So, for the use of longer detectors, some other parameter would have to be adjusted in order for the detector to work as desired. This could be done by e.g., increasing the filler content or increasing the layer thickness.

- The influence of temperature on the detector performance was also investigated. It was found that the response time of the detector linearly decreased with increasing temperature. The time required for the electric current to drop to half of its initial value ranged from $2 \mathrm{~min}$ at $35^{\circ} \mathrm{C}$ up to $10 \mathrm{~min}$ at $5{ }^{\circ} \mathrm{C}$. We conclude that the proposed detector is suitable for the whole measured temperature range. However, at lower temperatures, a slower response has to be considered.

- Unfortunately, the tested polymer composite was not sensitive to different oil amounts and so it is suitable only for detecting the presence of contamination, not its scale. The lowest detected amount of oil was as low as $0.01 \mathrm{~mL}$ droplet on the surface of water.

- It was shown that the detector layer adheres to all selected surfaces with sufficient strength, allowing potential application to various surfaces, depending on the actual use.

Author Contributions: Methodology, I.K.; investigation, M.P.; writing-original draft preparation, Z.Š.; supervision, I.K. and Z.Š.; project administration, Z.Š.; All authors have read and agreed to the published version of the manuscript.

Funding: This research was funded by Vedecká Grantová Agentúra MŠVVaŠ SR a SAV (VEGA 2/0051/20).

Acknowledgments: The authors want to thank Roland Mittelhammer from SGL Carbom to provide a sample of expanded graphite.

Conflicts of Interest: The authors declare no conflict of interest.

\section{References}

1. Hayakawa, K.; Nomura, M.; Nakagawa, T.; Oguri, S.; Kawanishi, T.; Toriba, A.; Kizu, R.; Sakaguchi, T.; Tamiya, E. Damage to and recovery of coastlines polluted with C-heavy oil spilled from the Nakhodka. Water Res. 2006, 40, 981-989. [CrossRef] [PubMed]

2. Lassalle, G.; Fabre, S.; Credoz, A.; Dubucq, D.; Elger, A. Monitoring oil contamination in vegetated areas with optical remote sensing: A comprehensive review. J. Hazard. Mater. 2020, 393, 122427. [CrossRef] [PubMed]

3. Amin Al Manmi, D.A.M.; Abdullah, T.O.; Al-Jaf, P.M.; Al-Ansari, N. Soil and Groundwater Pollution Assessment and Delineation of Intensity Risk Map in Sulaymaniyah City, NE of Iraq. Water 2019, 11, 2158. [CrossRef]

4. Page, C.A.; Bonner, J.S.; McDonald, T.J.; Autenrieth, R.L. Behavior of a chemically dispersed oil in a wetland environment. Water Res. 2002, 36, 3821-3833. [CrossRef]

5. Page, C.A.; Bonner, J.S.; Sumner, P.L.; McDonald, T.J.; Autenrieth, R.L.; Fuller, C.B. Behavior of a chemically-dispersed oil and a whole oil on a near-shore environment. Water Res. 2000, 34, 2507-2516. [CrossRef] 
6. Brekke, C.; Solberg, A.H.S. Oil spill detection by satellite remote sensing. Remote Sens. Environ. 2005, 95, 1-13. [CrossRef]

7. Fingas, M.; Brown, C. Review of oil spill remote sensing. Mar. Pollut. Bull. 2014, 83, 9-23. [CrossRef]

8. Lee, M.-S.; Park, K.-A.; Lee, H.-R.; Park, J.-J.; Kang, C.-K.; Lee, M. Detection and Dispersion of Thick and Film-Like Oil Spills in a Coastal Bay Using Satellite Optical Images. IEEE J. Sel. Top. Appl. Earth Obs. Remote Sens. 2016, 9, 5139-5150. [CrossRef]

9. Demori, M.; Ferrari, V.; Strazza, D.; Poesio, P. A capacitive sensor system for the analysis of two-phase flows of oil and conductive water. Sens. Actuators A Phys. 2010, 163, 172-179. [CrossRef]

10. Jung, K.K.; Choi, D.H.; Jung, I.D.; Lee, J.M.; Ko, J.S. Capacitive micro-oil detector with a nanotextured superhydrophobic/superoleophilic surface. Sens. Actuators B Chem. 2016, 237, 974-983. [CrossRef]

11. Strazza, D.; Demori, M.; Ferrari, V.; Poesio, P. Capacitance sensor for hold-up measurement in high-viscous-oil/conductive-water core-annular flows. Flow Meas. Instrum. 2011, 22, 360-369. [CrossRef]

12. Tonacci, A.; Corda, D.; Tartarisco, G.; Pioggia, G.; Domenici, C. A Smart Sensor System for Detecting Hydrocarbon Volatile Organic Compounds in Sea Water. CLEAN-Soil Air Water 2015, 43, 147-152. [CrossRef]

13. Fant, J.W.; Hansen, K.A. U.S. Coast Guard laser fluorosensor testing. In Proceedings of the 29th Arctic and Marine Oilspill Program (AMOP) Technical Seminar, Vancouver, BC, Canada, 6-8 June 2006.

14. Zhou, Z.; Guo, L.; Shiller, A.M.; Lohrenz, S.E.; Asper, V.L.; Osburn, C.L. Characterization of oil components from the Deepwater Horizon oil spill in the Gulf of Mexico using fluorescence EEM and PARAFAC techniques. Mar. Chem. 2013, 148, 10-21. [CrossRef]

15. Senga, H.; Kato, N.; Suzuki, H.; Akamatsu, T.; Yu, L.; Yoshie, M.; Tanaka, T. Field experiments and new design of a spilled oil tracking autonomous buoy. J. Mar. Sci. Technol. 2014, 19, 90-102. [CrossRef]

16. Tabačiarová, J.; Krajči, J.; Pionteck, J.; Reuter, U.; Omastová, M.; Mičušík, M. Styrene Butadiene Rubber/Carbon Filler-Based Vapor Sensors. Macromol. Chem. Phys. 2016, 217, 1149-1160. [CrossRef]

17. Yoon, H.; Xie, J.; Abraham, J.K.; Varadan, V.K.; Ruffin, P.B. Passive wireless sensors using electrical transition of carbon nanotube junctions in polymer matrix. Smart Mater. Struct. 2005, 15, S14-S20. [CrossRef]

18. Zhang, B.; Fu, R.W.; Zhang, M.Q.; Dong, X.M.; Lan, P.L.; Qiu, J.S. Preparation and characterization of gas-sensitive composites from multi-walled carbon nanotubes/polystyrene. Sens. Actuators B Chem. 2005, 109, 323-328. [CrossRef]

19. Daňová, R.; Olejnik, R.; Slobodian, P.; Matyas, J. The Piezoresistive Highly Elastic Sensor Based on Carbon Nanotubes for the Detection of Breath. Polymers 2020, 12, 713. [CrossRef] [PubMed]

20. Adhikari, P.; Bender, F.; Josse, F.; Ricco, A.J. Polymer-plasticizer coatings for shear horizontal-surface acoustic wave sensors for long-term monitoring of BTEX analytes in liquid-phase. In Proceedings of the 2016 IEEE International Frequency Control Symposium (IFCS), New Orleans, LA, USA, 9-12 May 2016; pp. 1-2.

21. Allouch, A.; Le Calvé, S.; Serra, C.A. Portable, miniature, fast and high sensitive real-time analyzers: BTEX detection. Sens. Actuators B Chem. 2013, 182, 446-452. [CrossRef]

22. Moghaddasi, A.; Sobolčiak, P.; Popelka, A.; Sadasivuni, K.K.; Spitalsky, Z.; Krupa, I. Electrically Conductive Electrospun Polymeric Mats for Sensing Dispersed Vegetable Oil Impurities in Wastewater. Processes 2019, 7, 906. [CrossRef]

23. Krupa, I.; Prostredný, M.; Špitalský, Z.; Krajči, J.; AlMaadeed, M.A.S. Electrically conductive composites based on an elastomeric matrix filled with expanded graphite as a potential oil sensing material. Smart Mater. Struct. 2014, 23, 125020. [CrossRef]

24. Nagata, K.; Iwabuki, H.; Nigo, H. Effect of particle size of graphites on electrical conductivity of graphite/polymer composite. Compos. Interfaces 1998, 6, 483-495. [CrossRef]

25. Panda, J.N.; Bijwe, J.; Pandey, R.K. Variation in size of graphite particles and its cascading effect on the performance properties of PAEK composites. Compos. Part B Eng. 2020, 182, 107641. [CrossRef]

26. Evgin, T.; Turgut, A.; Hamaoui, G.; Spitalsky, Z.; Horny, N.; Micusik, M.; Chirtoc, M.; Sarikanat, M.; Omastova, M. Size effects of graphene nanoplatelets on the properties of high-density polyethylene nanocomposites: Morphological, thermal, electrical, and mechanical characterization. Beilstein J. Nanotechnol. 2020, 11, 167-179. [CrossRef]

27. Kratochvíla, J.; Boudenne, A.; Krupa, I. Effect of filler size on thermophysical and electrical behavior of nanocomposites based on expanded graphite nanoparticles filled in low-density polyethylene matrix. Polymer Compos. 2013, 34, 149-155. [CrossRef] 
28. Boudenne, A.; Ibos, L.; Fois, M.; Majesté, J.C.; Géhin, E. Electrical and thermal behavior of polypropylene filled with copper particles. Compos. Part A Appl. Sci. Manuf. 2005, 36, 1545-1554. [CrossRef]

29. Boudenne, A.; Ibos, L.; Candau, Y. Thermophysical Properties of Multiphase Polymer Systems. In Handbook of Multiphase Polymer Systems; John Wiley \& Sons, Ltd.: Hoboken, NJ, USA, 2011; pp. 387-423. ISBN 978-1-119-97202-0.

30. Mamunya, Y.; Boudenne, A.; Lebovka, N.; Ibos, L.; Candau, Y.; Lisunova, M. Electrical and thermophysical behaviour of PVC-MWCNT nanocomposites. Compos. Sci. Technol. 2008, 68, 1981-1988. [CrossRef]

31. Wei, C.; Dai, L.; Roy, A.; Tolle, T.B. Multifunctional Chemical Vapor Sensors of Aligned Carbon Nanotube and Polymer Composites. J. Am. Chem. Soc. 2006, 128, 1412-1413. [CrossRef]

32. Kim, J.; Kim, K.S.; Kim, Y.H. Mechanical effects in peel adhesion test. J. Adhes. Sci. Technol. 1989, 3, $175-187$. [CrossRef]

33. Kinloch, A.J.; Lau, C.C.; Williams, J.G. The peeling of flexible laminates. Int. J. Fract. 1994, 66, 45-70. [CrossRef]

34. Poh, B.T.; Lee, P.G.; Chuah, S.C. Adhesion property of epoxidized natural rubber (ENR)-based adhesives containing calcium carbonate. Express Polym. Lett. 2008, 2, 398-403. [CrossRef]

35. Khan, I.; Poh, B.T. Effect of molecular weight and testing rate on adhesion property of pressure-sensitive adhesives prepared from epoxidized natural rubber. Mater. Des. 2011, 32, 2513-2519. [CrossRef]

(C) 2020 by the authors. Licensee MDPI, Basel, Switzerland. This article is an open access article distributed under the terms and conditions of the Creative Commons Attribution (CC BY) license (http://creativecommons.org/licenses/by/4.0/). 